\title{
Analysis on the Value of Project Teaching to the Cultivation of the Practical German Talent
}

\author{
Li Tian \\ Xi’an Fanyi University, Shaanxi, Xi’an, 710105
}

Keywords: project teaching; the cultivation of German talent; value

\begin{abstract}
As the development of the economic globalization, it is obvious that the requirements for talents of every country have been increasing. At present, China is in the period of rapid economic development, under this background, the higher education institutes, which undertake the important mission of cultivating the qualified talents for the development of China. Therefore, the institutes have cultivated the talents who are fit for the requirements of the society, and the actual requirements of the economic development can be satisfied. As a popular foreign language, Germany has a large number of learners in China, and the cultivation of practical German talents is also a focus in the field of education. Project teaching is a new teaching model in the new times. In the process of cultivating German talents in many colleges and universities, the application of the educational model has achieved good results. This paper briefly analyzes the value of project teaching for the cultivation of practical German talents, and may provides some suggestions to the cultivation of German talents in China.
\end{abstract}

At present, because of the rapid development of the economy in China, the practical talents who could make contributions to the future economic development in China are badly needed. Nowadays, because of the much stricter requirement for the German talents, the cultivation of the practical German talents has become a hot issue in the field of education; it not only requires the talents to have a good command of German, but also puts forward some new requirements to the talents such as the humanistic accomplishment, the moral quality, personality ability and so on ${ }^{[1]}$. Therefore, the requirements for the practical German talents become stricter in different aspects, and the requirements cannot be satisfied by finding talents via the simplex examination for testing the language ability of talents. These are not only necessary requirements of the social development, but also the new direction of the cultivation of talents. The core of the project teaching model is to improve students' comprehensive quality, to promote the improvement of students' personality, and to enhance students' comprehensive application ability. Combining with the practical application of project teaching, this paper discusses the significances of project teaching and its value in the cultivation of practical German talents.

\section{Connotation of the Cultivation of Practical German Talents}

The practical talents are the necessaries during the development of China; they are also the driving force of the economic development of China. As the rapid economic development of China, the requirements for the practical talents are increasing. As the important base of cultivating the practical talents, the colleges must explore the brand new approaches of cultivating the talents, and establish the system of cultivating the talents ${ }^{[2]}$. Practical talent, it means "a type of talent who can apply their professional knowledge and techniques to the special social practice that is related to their work". For the German major, it requires the students to master the basic German knowledge and techniques of social production and other social activities; at the sometime, the students can apply these knowledge and techniques skillfully so as to meet the need of the market. As a foreign language, German is very important to the further development of China; as the acceleration of the Open up Policy in China, the importance of the talents who master foreign language would be more obvious. So, the cultivation of the practical German talents is closely related to the economic development of China. In the actual development, the requirements to the practical German talents 
are not only mastering German knowledge but also skilled application, and the talents can create value by means of applying the knowledge; so the practical German talents have some features as below: solid foundation, strong professional skills, wide knowledge, strong practical ability, high comprehensive quality and so on.

\section{The Practical Application of Project Teaching in the Cultivation of Practical German Talents}

The core of the project teaching is to improve the students' all round development, so it has the features of comprehensiveness and pertinence; essentially, the project teaching is launched by the form of a plan or a task, the teachers and the students participate in the project and accomplish the task in an effective manner ${ }^{[3]}$. It should be noted that the plan can be set up by teachers and also can be set by teachers and students together, but in the process of actual implementation of the plan or task, teachers and students should cooperate, communicate with each other so as to accomplish the plan or task within the specified time. It can be seen that the core of project teaching is students, and the focus of task implementation is also taking the students as the centre. In the process of carrying out the actual project, students can learn more knowledge, they must work hard to collect information according to the task goals, and these are good for the all-round development of the students. The basic implementation steps of project teaching are as follows: (1) Start-up stage. In this stage, the subject could be chosen or set up by the teachers, or by the teachers and the students together; the subject must be challenging, all round, and practical. In addition, it must make sure who the leader is in the project, and the following stages will be organized by the leader. (2) Entry stage. All the participators should follow the leader and they will be divided into groups, and continue the following activities according to the subject that has been decided previously. The main function of this stage is to cultivate the students' ability of information expression and social communication. (3) Plan-making stage. In this stage, it is necessary to make the detailed plan of fulfilling the task according to the subject that has been set up previously; the details include way of fulfillment, project location, time limit, required materials, etc. On the other hand, the tasks should be assigned to the members according to the actual specialty of every member, and then the project could be launched after reaching an agreement. (4) Plan-implementing stage. In this stage, the team members should collect and sort out the relevant materials according to the subject and the planned tasks, so as to acquire some effective information; at the some time, it is very important to carry out market research, and to acquire some relevant data so as to fulfill the task in minimum time; and then, reach the final output together by the endeavors of all the members. (5) Achievement elaboration stage. In this stage, every group could share their achievement with others, so that every group could learn from others, appreciate others, and understand others. (6) Project evaluation stage ${ }^{[4]}$. It is necessary to evaluate the actual result of the project, score the process of the project and the final result; and then, to find out the problems in the whole project process, to exchange and feedback. At this stage, the teacher should give appropriate comments on the performance of the group, and evaluate the comprehensive problems in the process of the project development, and the problems should be used as a basis for improvement in the next project.

\section{Value of Project Teaching to the Cultivation of Practical German Talent}

By the analysis of the previous two parts in this paper, it can be seen that the project teaching has the comprehensive value for the cultivation of the practical German talents. First of all, the project teaching has a high degree of conformity with the current training system of practical German talents, so the application of project teaching is more feasible. Second, the training of practical German talents is stricter in the use of German language knowledge, and the project teaching is closely related to the actual employers' needs of the relevant industries, and the some time, the purpose of project teaching is strong, so it can transform students' basic knowledge into the ability of solving the practical problems. Furthermore, Project teaching focuses on guiding students, but forcing them to study hard; it can help the students to solve practical problems by using scientific 
methods, give students more space to improve themselves by their own, ask the teachers to pay attention to the cultivation of students' sense of responsibility, and improve the students' self-management ability in teaching activities. At last, The application of project teaching pays attention to the lifelong development of students, and it can promote the students' lifelong learning consciousness in the course of project establishment and practical teaching, especially in the future work, students need to improve their all round ability in many aspects such as ability of communication and coordination, ability of team work, conflict resolution ability and so on. In a word, the project teaching has high comprehensive value for the cultivation of practical German talents, so long as the project is set up reasonably and scientifically, the ideal teaching goal can be achieved.

The project teaching not only has comprehensive value for the cultivation of applied German talents, but also has a strong promoting effect on students' actual learning, mainly in the following aspects :(1) It can promote and improve the German language ability of the students; in the current market development, German talents are required to have a solid foundation of German, and they must have strong ability of listening, speaking, translating, and communication, at the some time, the accuracy is also important during the application. The project teaching is mostly carried out in small groups, students can strengthen their German ability according to their own weaknesses in the actual learning process, and then set up the project that aims for improving their weakness, so as to promote and improve their German ability. (2) To promote the understanding of the relevant industrial knowledge and ability so that the students can learn German on the basis of understanding these knowledge and ability. In the process of data collection and integration, the project teaching can effectively integrate the knowledge with the industry, so that the students can master the basic knowledge, terminology, skills and basic working methods of the relevant industries in the process of learning, it can promote the students' adaptability in their future career life. (3) Promoting the improvement of students' Learning ability comprehensively. Each stage of the project teaching can promote the students' learning ability, including multicultural communication ability, practical ability, language ability, frustration resistance ability, and teamwork ability, etc. (4) promoting the all-round quality of students and helping the formation of students' professional attainment. Project teaching is a student-oriented teaching model, in the process of teaching, the teacher whose mainly role is a guider should pays more attention to the formation of students' thoughts, qualities, self-confidence, honesty, dedication and other personality. The project teaching method takes the students as a center, it effectively avoids the disadvantages of the traditional infusion teaching, and it has important significance for the German learners.

It is feasible to apply project teaching in the cultivation of German talents, and its advantage is prominent. In practical application, the advantage is shown in the following aspects: (1) The whole process of project teaching is student-oriented; student-oriented emphasizes the all-round development of students. In the actual teaching process, the teacher plays the role of a guider; at the some time, the students have enough space for self-learning. When the students have questions and problems, the teacher can give them support and help, so that the students can effectively manage themselves and learn by themselves. In project teaching, students should choose the proper partners in group, and know what tasks they will accomplish in their study, and learn to start their study with certain objective and plan ${ }^{[5]}$. (2) Project teaching is closely related to real life. In the process of collecting materials and information, the project teaching will closely tie the reality to students' life, and effectively integrate the situations of the talents with the present market; these will be helpful to the development of actual teaching activities. The project should be designed to solve the actual problems in life as the starting point, so that the students can learn more knowledge in the process of fulfill the task. (3) The content of the project should be diverse, and the place of implementation also should not be limited into campus. The students should do some social investigations before they set up the subject of the project, only by this could they acquire the relevant data for statistics, and could they acquire useful information. These are helpful to the cultivation of the students' practical ability. (4) Improving students' interest in learning. The traditional teaching model pays attention to the study of theoretical knowledge, so the students' may easily feel tired and boring in 
the long learning process; but the project teaching can deepen the communication between students and students, promote the communication between students and teachers, they could discuss problems together, study together, in the end, it can fully arouse students' interests, and promote them to participate in German learning independently.

\section{References}

[1] Bian Chao. Research on the Cultivation Model of College German Talents from the Perspective of Internationalization----Taking the Intercollegiate Exchange Project of German Department of Beijing Foreign Studies University as an Example[J]. Beijing Education (Higher Education), 2016, 03: 53-55.

[2] Zhang Jie, Ji Tingting. The Reference Significance of German Dual System Education Model to the Development of the Undergraduate Whose Major is German in Zhejiang Province [J]. Journal of Lanzhou Jiaotong University, 2016,02: 128-131.

[3] Zhu Huidong, Hou Yujing. On Reform and Innovation of the German Language Talent Training Model for Undergraduate Who Majoring German[J]. KE JI \& GUAN LI, 2016, 03: 182-183.

[4] Cao Xia. Exploration on the Teaching Reform of German Majors in Colleges and Universities under the Mode of School-enterprise Cooperation---- From the Perspective of German Teaching Reform in Xiangtan University[J]. Theory and Practice of Contemporary Education, 2016, 08: 137-140.

[5] Ma Lili. Exploration on the Training Model of German Major in Higher Vocational Colleges under the Background of International Cooperation[J]. Education Modernization, 2018, 03: 20-21. 